\title{
ECC
}

\section{Computational study of substituent effect on the electronic properties of ferrocylidene acetophenones complexes}

\section{Maryam Rahimia, Saeid Jamehbozorgib,*, Henry Chermettec, Reza Ghiasid, Mahboubeh Poor Kalhore}

a Department of chemistry, faculty of science, Arak branch, Islamic Azad University, P.O. BOX 383611-9131, Arak, Iran

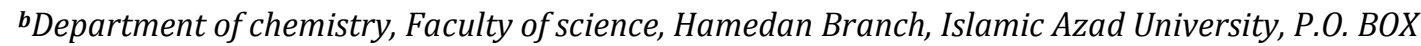
65181-15743, Hamedan, Iran

'Institut des sciences analytiques, Université Claude Bernard LYON-1, Lyon, CNRS UMR 5280, 43 boul. du 11 Nov. 1918, 69622 Villeurbanne, France

'Department of Chemistry, Faculty of science, East Tehran Branch, Islamic Azad University, P.O.BOX 16511-53311, Tehran, IRAN

eDepartment of Chemistry, faculty of Science, Farhangian University, Tehran, Iran

Received: 12 March 2019, Accepted: 28 April 2019, Published: 1 September 2019

\begin{abstract}
In this study, the substituent effect on the electronic, spectroscopic properties and thermodynamic parameters of neutral and oxidized states of ferrocylidene acetophenone complexes is investigated by adopting the hybrid meta exchangecorrelation functional of M06-2X. The frontier orbitals and the highest occupied molecular orbitals-lowest unoccupied molecular orbitals gaps of the substituted compounds are determined. Ionization potential (IP), electron affinity, and reorganization energy values of these molecules are estimated. The thermodynamic parameters (free energy and enthalpy) of the oxidation reaction of the studied complexes are calculated. Also, a variation on the wavenumber of carbonyl group in both states is revealed as the correlations between the evaluated properties and Hammett's constant are explored.
\end{abstract}

Keywords: Ferrocene; substituent effect; ionization potential; electron affinity; thermodynamic parameters.

\section{Introduction}

Ferrocene and its derivatives are wellknown redox active materials and have been extensively used to fabricate modified electrodes for electrochemical sensors and biosensors. Substituting the functional groups of ferrocene offers the prospect of controlling its properties, such as its solubility, stability, oxidation potential, and reversibility of oxidation wave (important for its role as an electron transfer mediator). Adjusting the outlined molecular properties is essential for biosensor applications. In this respect, different ferrocene derivatives have been developed. In this sense, the electrochemistry of some 
ferrocene derivatives have been studied, and the redox potential and substituent effects have been reported [1].

As the most straightforward method of the adjusting ferrocene properties is substitution, many studies have reported the effect of different substituents on the chemical and physical characteristics of ferrocene. Such studies can be facilitated by quantum chemical (QC) evaluations since they are useful in relating structural changes to electronic properties [2-7]. That is why various computational investigations have reported the impact of substituting diverse functional groups on the structural, spectroscopic, and electronic features of organometallic complexes [8-20]. Furthermore, quantum chemistry can provide quantitative scales of the substituent parameters to clarify the steric or polar effects of the utilized substituents on different molecular properties. For example, the Hammett constant $\left(\sigma_{\mathrm{p}}\right)$ [21] can describe the electronic effects of the substituted functional groups on the equilibrium and rate constants of a reacting molecule. In this investigation, we studied the substituent effect on the electronic properties and thermodynamic parameters of the neutral and oxidized states of ferrocylidene acetophenone complexes using the M06-2X method.

\section{Computational methods}

The QC calculations were performed using the Gaussian 09 program [22]. While the main group elements of the compounds were described by the standard basis set of $6-311 \mathrm{G}(\mathrm{d}, \mathrm{p})$, the Fe element was considered using the standard Def2-TZVPPD basis set [23]. The geometries of the compounds were optimized by the hybrid functional of M062X, as developed by Truhlar and Zhao [24]. This method is hybrid meta exchange-correlation functionals. The M06-2X functional is a highnonlocality functional with double the amount of nonlocal exchange (2X). Substituents are $\mathrm{F}, \mathrm{Cl}$, and $\mathrm{CN}$, and EDG substituents are $\mathrm{OH}$ and Me.Table 1 shows the absolute energy of the neutral and oxidized states of these complexes. Illustration of the substituent effect on the electronic properties in this study has been reported. EWG Adiabatic ionization potential (IP(a)), an optimized structure for both the neutral and charged molecule) and vertical IP(v), (at the geometry of the neutral molecule) values were calculated for these molecules.

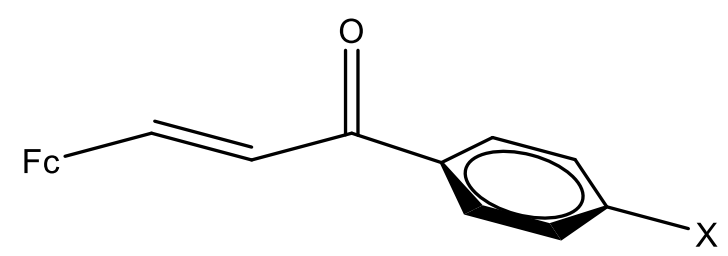

Figure 1.The structure of ferrocylidene acetophenones complexes ( $\mathrm{X}=$ substituent $)$

\section{Ionization potential}

Figure 1 displays the structures of the studied ferrocene derivatives. We selected electron-withdrawing groups
(EWG) and electron-donating groups (EDG) for The IP(a) and IP(v) values, which were larger for molecules containing EWGs than for those having 
EDGs (Table 1). A good linear correlation was seen between the IP values and the $\sigma_{\mathrm{p}}$ Hammett constants (Figure 2):

$$
\begin{gathered}
I P(a)=0.2325 \sigma_{p}+7.3036 ; R^{2} \\
=0.9612 \\
I P(v)=0.2349 \sigma_{p}+7.3487 ; R^{2} \\
=0.9542
\end{gathered}
$$

Electron affinity

Adiabatic and vertical electron affinity values of the studied ferrocene derivatives have been summarized in Table 1. It can be seen that the EA(a) and $E A(v)$ values are smaller for molecules containing EWGs than for those having EDGs. A good linear correlation is seen between the EA values and the $\sigma_{\mathrm{p}}$ Hammett constants:

$$
\begin{gathered}
E A(\boldsymbol{a})=-0.6462 \sigma_{p}-0.8788 ; R^{2} \\
=0.9347 \\
E A(v)=-0.6950 \sigma_{p}-0.6234 ; R^{2} \\
=0.9343
\end{gathered}
$$
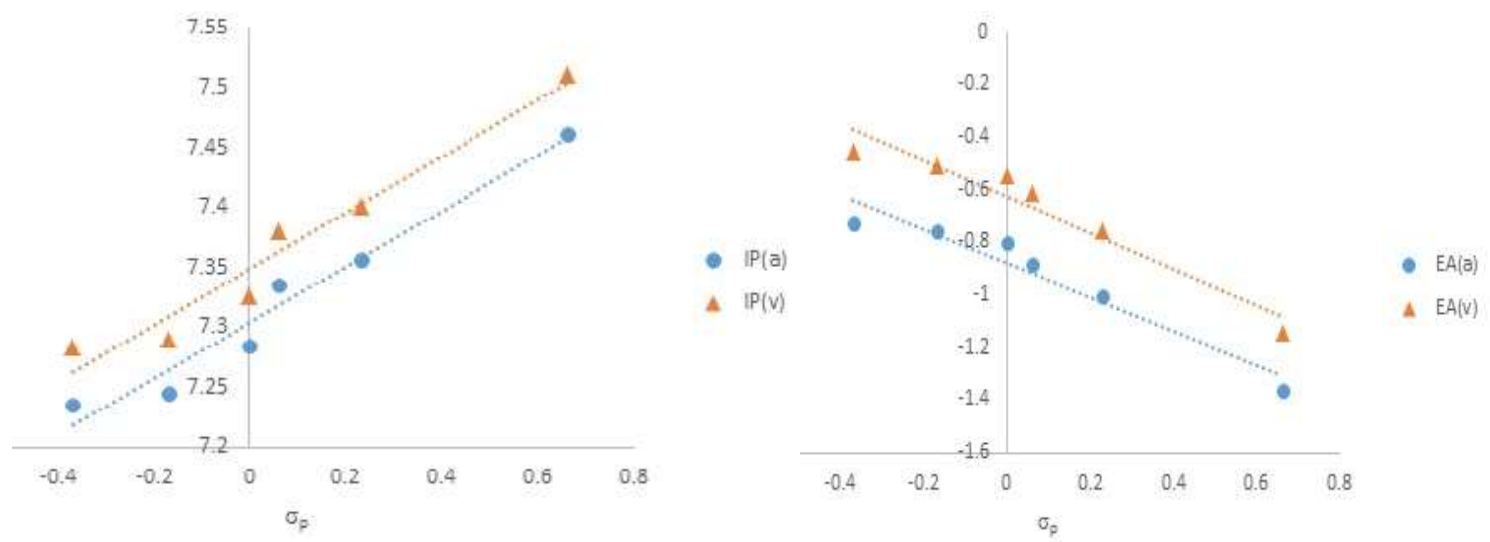

Figure 2. Dependencies of vertical, adiabatic ionization potential (IP), vertical and adiabatic electron affinity (EA) values on the Hammett's constant in the ferrocylidene acetophenones complexes

Table 1. Adiabatic ionization potential (IP(a), eV), vertical ionization potential (IP(v), eV), Adiabatic electron affinity $(\mathrm{EA}(\mathrm{a}), \mathrm{eV})$ and vertical electron affinity $(\mathrm{EA}(\mathrm{v}), \mathrm{eV})$ values of the studied

\begin{tabular}{cccccc} 
ferrocylidene acetophenones. $\sigma_{\mathrm{p}}$ values are Hammett's constant \\
\hline $\mathbf{X}$ & $\sigma_{\mathbf{p}}$ & $\mathbf{I P ( a )}$ & $\mathbf{I P}(\mathbf{v})$ & $\mathbf{E A}(\mathbf{a})$ & $\mathbf{E A}(\mathbf{v})$ \\
\hline $\mathrm{OH}$ & -0.37 & 7.24 & 7.28 & -0.73 & -0.45 \\
$\mathrm{Me}$ & -0.17 & 7.25 & 7.29 & -0.76 & -0.51 \\
$\mathrm{H}$ & 0.00 & 7.28 & 7.33 & -0.80 & -0.54 \\
$\mathrm{~F}$ & 0.06 & 7.33 & 7.38 & -0.88 & -0.62 \\
$\mathrm{Cl}$ & 0.23 & 7.36 & 7.40 & -1.00 & -0.76 \\
$\mathrm{CN}$ & 0.66 & 7.46 & 7.51 & -1.36 & -1.15 \\
\hline
\end{tabular}



Electron reorganization energy

( $\lambda$ electron)

The $\lambda_{\text {electron }}$ can be expressed as follows:

$$
\lambda_{\text {electron }}=\boldsymbol{E E P}-\boldsymbol{E A}(\boldsymbol{v})
$$

EEP (electron extraction potential) is the energy difference from $\mathrm{E}$ to $\mathrm{E}^{-}$ (anionic), using $\mathrm{E}^{-}$geometric structure in calculation $[25,26]$. It can be seen that the $\lambda_{\text {electron }}$ values are larger for molecules containing EWGs than for those having EDGs (Table 2).

\section{Hole reorganization energy $\left(\lambda_{\text {hole }}\right)$}

$\lambda_{\text {hole }}$ for hole transfer can be expressed as follows:

$$
\lambda_{\text {hole }}=I P(v)-H E P
$$

HEP (hole extraction potential) is the energy difference from $E$ (neutral molecule) to $\mathrm{E}^{+}$(cationic), using $\mathrm{E}^{+}$ geometric structure in calculation. It can be seen that the $\lambda_{\text {hole }}$ values are larger for molecules containing EWGs than those having EDGs. The mobility of charges has been established to be related mainly to the internal reorganization energy $\lambda_{\text {hole/electron }}$.

The data in Table 2 show that the $\lambda_{\text {hole }}$ values for all molecules are less than their corresponding $\lambda_{\text {electron }}$ values, which indicates the electron transfer rate is slower than the hole transfer rate.

Table 2. Electron Extraction potential (EEP, eV), hole Extraction potential (HEP, eV), Electron reorganization energy $\left(\lambda_{\text {electron }}, \mathrm{eV}\right)$ and Hole reorganization energy $\left(\lambda_{\text {hole }}, \mathrm{eV}\right)$ values of the studied ferrocylideneacetophenones

\begin{tabular}{ccccc}
\hline $\mathbf{X}$ & HEP & $\lambda_{\text {hole }}$ & EEP & $\lambda_{\text {electron }}$ \\
\hline $\mathrm{OH}$ & 7.19 & 0.09 & 1.04 & 1.49 \\
$\mathrm{Me}$ & 7.20 & 0.09 & 1.05 & 1.56 \\
$\mathrm{H}$ & 7.24 & 0.08 & 1.09 & 1.64 \\
$\mathrm{~F}$ & 7.28 & 0.09 & 1.18 & 1.80 \\
$\mathrm{Cl}$ & 7.31 & 0.10 & 1.26 & 2.02 \\
$\mathrm{CN}$ & 7.42 & 0.09 & 1.58 & 2.73 \\
\hline
\end{tabular}

\section{Vibrational analysis}

The wavenumber values of carbonyl stretching of the studied complexes for neutral and oxidized states are listed in Table 3. It can be found that these values increase in the presence of the EWGs. In contrast, $v(\mathrm{CO})$ values decrease in the presence of EDGs. On the other hand, $v(\mathrm{CO})$ values are higher in the oxidized than in the neutral state.

\section{Thermodynamic parameters}

The thermodynamic parameters of the oxidation ferrocylidene acetophenone complexes are shown in Table 4. It can be seen that the oxidation reaction is not spontaneous. On the other hand, $\Delta H$ values reveal that this reaction is endothermic. The dependencies of the thermodynamic parameters on the Hammett's constant were explored. The linear correlations were:

$$
\begin{gathered}
\Delta G=7.903 \sigma_{p}+166.95 ; R^{2} \\
=0.9064 \\
\begin{aligned}
\Delta H=5.4719 \sigma_{p}+167.22 ; R^{2} \\
=0.9619
\end{aligned}
\end{gathered}
$$


It can be found that the thermodynamic parameters are higher in the presence of EWGs as compared to that in the presence of EDGs.

\section{Analysis of molecular orbitals}

The frontier orbital energy values and their gap of the studied complexes in the neutral and oxidized states are given in Table 5. It can be seen that in the presence of $\mathrm{X}=\mathrm{EWGs}$, the highest occupied and lowest unoccupied molecular orbitals (HOMO and LUMO, respectively) are more stable as compared to that in the presence of EDGs. It can be found that the HOMOLUMO gap is reduced when $\mathrm{X}=$ EWGs.

Table 3. The wavenumber values $\left(\mathrm{cm}^{-1}\right)$ of carbonyl stretching of thestudied ferrocylidene acetophenones

\begin{tabular}{ccc}
\hline $\mathbf{X}$ & $\boldsymbol{v}(\mathbf{C O})$, neutral & $v(\mathbf{C O})$, oxidized \\
\hline $\mathrm{OH}$ & 1790.3097 & 1795.4800 \\
$\mathrm{Me}$ & 1794.0735 & 1801.9298 \\
$\mathrm{H}$ & 1795.9526 & 1807.0277 \\
$\mathrm{~F}$ & 1793.8530 & 1804.1256 \\
$\mathrm{Cl}$ & 1796.4697 & 1804.6933 \\
$\mathrm{CN}$ & 1800.3199 & 1813.0268 \\
\hline
\end{tabular}

Table 4. Thermodynamic values $(\Delta \mathrm{G}, \Delta \mathrm{H})(\mathrm{kj} / \mathrm{mol})$ of the studied ferrocylidene acetophenones in the neutral and oxidized states

\begin{tabular}{|c|c|c|c|c|c|c|}
\hline \multirow[b]{2}{*}{$\mathbf{X}$} & \multicolumn{2}{|c|}{ neutral } & \multicolumn{2}{|c|}{ oxidized } & \multirow[b]{2}{*}{$\Delta \mathbf{G}$} & \multirow[b]{2}{*}{$\Delta \mathbf{H}$} \\
\hline & $\mathbf{G}$ & $\mathbf{H}$ & $\mathbf{G}$ & $\mathbf{H}$ & & \\
\hline $\mathrm{OH}$ & -2147.3576 & -2147.2891 & -2147.0951 & -2147.0256 & 164.72 & 165.36 \\
\hline $\mathrm{Me}$ & -2111.4195 & -2111.3497 & -2111.1565 & -2111.0857 & 165.02 & 165.62 \\
\hline $\mathrm{H}$ & -2072.1380 & -2072.0719 & -2071.8743 & -2071.8049 & 165.48 & 167.53 \\
\hline $\mathrm{F}$ & -2171.3861 & -2171.3181 & -2171.1177 & -2171.0505 & 168.41 & 167.94 \\
\hline $\mathrm{Cl}$ & -2531.7489 & -2531.6796 & -2531.4794 & -2531.4113 & 169.09 & 168.35 \\
\hline $\mathrm{CN}$ & -2164.3794 & -2164.3076 & -2164.1050 & -2164.0354 & 172.20 & 170.76 \\
\hline
\end{tabular}

A study of linear correlation seen between the frontier orbital energy and the $\sigma_{\mathrm{p}}$ Hammett constants in the neutral state showed the following correlations:

$$
\begin{gathered}
E(\text { HOMO })=-0.0331 \sigma_{p}-0.3883 ; R^{2} \\
=0.7783 \\
E(\text { LUMO })=-0.0085 \sigma_{p}-0.2154 ; R^{2} \\
=0.9632
\end{gathered}
$$


Therefore, there is a good linear correlation between the E(LUMO) energy and the $\sigma_{\mathrm{p}}$ Hammett constants in the neutral states. On the other hand, oxidation results in an increase in the stability of frontier orbitals and a decrease of the HOMO-LUMO gap values. A good linear correlation was seen between the frontier orbital energy and the $\sigma_{\mathrm{p}}$ Hammett constants in the oxidized states:

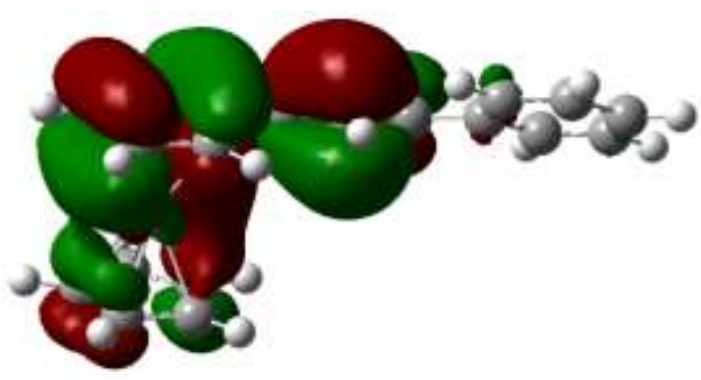

HOMO

$$
\begin{gathered}
E(H O M O)=-0.012 \sigma_{p}-0.2826 ; R^{2} \\
=0.9705 \\
E(L U M O)=-0.0271 \sigma_{p}-0.0435 ; R^{2} \\
=0.9408
\end{gathered}
$$

Figure 3 presents plots of frontier orbitals in the ferrocylidene acetophenone complex $(\mathrm{X}=\mathrm{H})$. It can be found that the ferrocene fragment has more contribution in HOMO than in LUMO.

Figure 3. Plots of frontier orbitals in the ferrocylidene acetophenone complex $(X=H)$

Table 5. Frontier orbital energy (eV) and HOMO-LUMO gap (eV) values of the studied ferrocylidene acetophenones in the neutral and oxidized states

\begin{tabular}{cccccccc}
\hline & \multicolumn{3}{c}{ neutral } & & \multicolumn{3}{c}{ oxidized } \\
\cline { 2 - 3 } $\mathbf{X}$ & $\mathbf{E}_{\text {(номо) }}$ & $\mathbf{E}_{\text {(Lumo) }}$ & Gap & & $\mathbf{E}_{\text {(номо) }}$ & $\mathbf{E}_{\text {(Lumo) }}$ & Gap \\
\hline $\mathrm{OH}$ & -7.59 & -1.00 & 6.58 & & -10.06 & -5.80 & 4.26 \\
$\mathrm{Me}$ & -7.61 & -1.05 & 6.56 & & -10.45 & -5.81 & 4.64 \\
$\mathrm{H}$ & -7.66 & -1.11 & 6.55 & & -10.80 & -5.85 & 4.95 \\
$\mathrm{~F}$ & -7.73 & -1.18 & 6.55 & & -10.76 & -5.88 & 4.88 \\
$\mathrm{Cl}$ & -7.77 & -1.31 & 6.46 & & -10.58 & -5.90 & 4.68 \\
$\mathrm{CN}$ & -7.90 & -1.74 & 6.16 & & -11.13 & -6.03 & 5.10 \\
\hline
\end{tabular}

\section{Conclusion}

The computational study of substituent effect on the electronic properties of ferrocylidene acetophenone complexes showed that, EA(a) and EA(v) values are smaller for molecules containing EWGs than for those having EDGs. $\operatorname{IP}(\mathrm{a})$ and $\operatorname{IP}(v)$ values are larger for molecules containing EWGs than for those having EDGs. The $\lambda_{\text {hole }}$ values for all molecules are less than their corresponding $\lambda_{\text {electron }}$ values indicating that the electron-transfer rate is slower than the hole transfer rate. Oxidation results in increasing the stability of frontier orbitals and decreasing the HOM-LUMO gap values. v(CO) values increase in the presence of the EWGs. In contrast, $\mathrm{v}(\mathrm{CO})$ values decrease in the presence of EDGs. On the other 
hand, $v(\mathrm{CO})$ values are higher in the oxidized state than in the neutral one. On the basis of the thermodynamic parameters, the oxidation reaction is not spontaneous but endothermic.

\section{Acknowledgements}

We gratefully acknowledge the financial support from the Research Council of Arak branch, Islamic Azad University.

\section{References}

[1] S.M. Batterjee, M.I. Marzouk, M.E. Aazab, A. El-Hashash, Appl. Organometal. Chem., 2003, 17M, 291297.

[2] A. Stockmann, J. Kurzawa, N. Fritz, N. Acar, S. Schneider, J. Daub, R. Engl, T. Clark, J. Phys. Chem. A., 2002, 106, 7958-7970.

[3] M. Ottonelli, M. Piccardo, D. Duce, S. Thea, G. Dellepiane, J. Phys. Chem. A., 2012, 116, 611-630.

[4] Y.H. Cheng,Y. Fang, X. Zhao, L. Liu, Q.X. Guo, Bull. Chem. Soc. Jpn., 2002, 75, 1715-1722.

[5] F. Pichierri, Theor. Chem. Acc., 2017, 136, 114-123.

[6] G.S. Remya, C.H. Suresh, phys.Chem.Chem.Phys., 2016, 18, 20615-20626.

[7] H. Szatylowicz, A. Jezuita, T.Siodła, K.S. Varaksin, M.A. Domanski, K. Ejsmont, T.M. Krygowski, ACS Omega, 2017, 2, 7163-7171.

[8] R. Ghiasi, A.zamani, J. Chin. Chem. Soc., 2017, 64, 1340-1346.

[9] R. Ghiasi, H. Pasdar, S. Fereidoni, Russian J. Inorg. Chem., 2016, 61, 327333.

[10] R. Ghiasi, A. Heydarbeighi, Russian J. Inorg. Chem., 2016, 61, 985992.

[11] R. Ghiasi, H. Pasdar, F. Irajizadeh, J. Chil. Chem. Soc, 2015, 60, 27402746.
[12] R.Ghiasi, S.Abdolmohammadi, S. Moslemizadeh, J. Chin. Chem. Soc., 2015, 62, 898-905.

[13] A. Peikari, R. Ghiasi, H. Pasdar, Russian J. Phys. Chem. A, 2015, 89, 250-255.

[14] R. Ghiasi, E. Amini, J. Struc. Chem., 2015, 56, 1483-1494.

[15] M.Z. Fashami, R. Ghiasi, J. Struc. Chem., 2015, 56, 1474-1482.

[16] R. Ghiasi, A. Boshak, J. Mex. Chem. Soc., 2013, 57, 8-15.

[17] H. Pasdar, R. Ghiasi, Main Group Chem., 2009, 8, 143-150.

[18] (a) A.N. Egorochkin, O.V. Kuznetsova, N.M. Khamaletdinova, L.G. Domratcheva-Lvova, Inorganica Chim. Acta, 2018, 471, 148-158; (b) S. Sajjadifar, Chemical Methodologies, 2017, 1, 1-11.

[19] H. Anane, S.E. Houssame, A.E. Guerraze, A. Guermoune, A. Boutalib, A. Jarid, I. Nebot-Gil, F. Tomás, Cent. Eur. J. Chem., 2008, 6, 400-403.

[20] M.H. Fekri, A. Omrani, S. Jamehbozorgi, M. Razavi mehr, Advanced Journal of Chemistry-Section A, 2019, 2, 14-20.

[21] L.P. Hammett, J. Am. Chem. Soc. , 1937, 59, 96-103.

[22] M.J. Frisch, G.W. Trucks, H.B. Schlegel, G.E. Scuseria, M.A. Robb, J.R. Cheeseman, G. Scalman,V. Barone, B. Mennucci, G.A. Petersson, H. Nakatsuji, M. Caricato, X. Li, H.P. Hratchian, A.F. Izmaylov, J. Bloino, G. Zheng, J.L. Sonnenberg, M. Hada, M. Ehara, K. Toyota, R. Fukuda, J. Hasegawa, M. Ishida, T. Nakajima, Y. Honda, O. Kitao, H. Nakai, T. Vreven, J.A. Montgomery, Jr., J.E. Peralta, F. Ogliaro, M. Bearpark, J.J. Heyd, E. Brothers, K.N. Kudin, V.N. Staroverov, R. Kobayashi, J. Normand, K. Raghavachari, A. Rendell, J.C. Burant, S.S. Iyengar, J. Tomasi, M. Cossi, N. Rega, J.M. Millam, M. Klene, J.E. Knox, J.B. Cross, V. Bakken, C. 
Adamo, J. Jaramillo, R. Gomperts, R.E. Stratmann, O. Yazyev, A.J. Austin, R. Cammi, C. Pomelli, J.W. Ochterski, R.L. Martin, K. Morokuma, V.G. Zakrzewski, G.A. Voth, P. Salvador, J.J. Dannenberg, S. Dapprich, A.D. Daniels, O. Farkas, J.B. Foresman, J.V. Ortiz, J. Cioslowski, D.J. Fox, Revision A.02 ed.; Gaussian, Inc.: Wallingford CT, 2009.

[23] D. Rappoport, F. Furche, J. Chem.

Phys., 2010, 133, 134105-134115.

How to cite this manuscript: Maryam Rahimi, Saeid Jamehbozorgi, Henry Chermette, Reza Ghiasi, Mahboubeh Poor Kalhor. "Computational study of substituent effect on the electronic properties of ferrocylidene acetophenones complexes". Eurasian Chemical Communications, 2019, 411-418. 